\title{
ETNOGRAFÍA ANTROPOLÓGICA MEMORIA Y TRADICIÓN DE QASIRI WARMI LLAQTA
}

\author{
Informe de autoría colectiva
}

\section{Introducción}

El propósito del trabajo de campo del curso de Antropología de la Religión es aproximarnos al pensamiento andino de la Comunidad campesina de Qasiri, en el distrito de Pauza, Ayacucho, mediante la memoria y la tradición de sus migrantes a Lima. En este caso, la tradición religiosa a la Virgen de las Nieves constituye no solo un pretexto de cohesión de los hijos migrantes de Qasiri, sino una forma de fortalecer y socializar la identidad cultural andina.

Vigorizar la Asociación Progresista de los Hijos de Qasiri por constituir un órgano central que unifica a todo cuanto migra a Lima y se dispersa en los barrios de la capital, con sus distintas actividades y formas de vida. Por lo que la institución se convierte en un ente cohesionador, protector y reproductor del sistema de valores propios de la comunidad de origen.

Este hecho constituye una tradición porque a través de la fiesta patronal del Culto a la Virgen de las Nieves se socializa con las siguientes generaciones como un proceso de endoculturación para preservar, difundir y reclamar el derecho cultural de los pueblos andinos en este proceso de la globalización del mundo.

Por lo tanto, en la estructura de las tres partes del presente trabajo etnográfico encontraremos las entrevistas participantes de nuestros estudiantes a manera de diálogo con los actores sociales, quienes manifiestan no lo que están reproduciendo en el nuevo espacio, sino lo que sucedió o realizaron en el mismo escenario de la Comunidad de Qasiri. Incluso, los mitos del Apu Sara-Sara o los relatos de la Virgen de las Nieves son como algo sucedido en el tiempo, donde ambas personajes parecen duplicarse o refundirse en una de ellas, como un intento de legitimar la tradición y la población. 


\section{Parte I}

Pimentel Sánchez, Nekson

Prado Quispe, Victoria

Horna Rojas, Vanessa

Chávez de la Cruz, Becky

Villanueva Espino, Ebert

\section{Reseña histórica del pueblo de qasiri ${ }^{1}$}

Casire es una comunidad ubicada en el sur andino peruano, anexo del distrito de Pausa, provincia de Paucar del Sara Sara, departamento de Ayacucho.

Casire provendría del término quechua "Qasiri”, que significa, de acuerdo a nuestros entrevistados, "pueblo de piedra" o "pueblo sobre la piedra". Este término habría sido pronunciado por la Virgen de la Nieves, patrona de Qasire.

El origen de esta comunidad se remonta a tiempos desconocidos, pero desde la visión de sus mismos pobladores Qasiri se originó sobre un espacio geográfico agreste, rodeada por pedregales, pendientes y montañas azuladas y grises. Por las características del terreno, los pobladores desarrollaron la agricultura, principalmente frutas: lúcumas, duraznos y la tuna. En otras palabras, la agricultura es la base económica, debido a la riqueza mineral de sus suelos, en el que el maíz es uno de los productos imprescindibles para el sostenimiento de la comunidad.

Los productos pueden distribuirse de dos formas: autoconsumo e intercambio. Entre ellos destaca el sistema de intercambio porque a partir de él se daba la interrelación entre los distintos pueblos. Para ello, los hombres viajaban a otras comunidades ubicadas a varios días de camino para hacer el trueque con otras especies que no se produce en los suelos de Qasiri. Cuando los hombres realizaban viajes prolongados, las mujeres asumían los quehaceres domésticos, las actividades productivas y las responsabilidades políticas; razón por la cual Qasiri fue vista por los forasteros como pueblo de mujeres. Además, los niños morían frecuentemente con la viruela y el paludismo.

En una comunicación personal, el Arq. Alberto Bueno ${ }^{2}$ nos comentó que Qasiri podría ser de la época preinca, porque toda la región sur de Ayacucho formó parte del el imperio de los incas. Mientras don Filiberto García Cuellar refiere sobre la existencia de las chullpas con los restos de entierro y cree que es de la época inca: "En el trayecto del camino a Qasiri, encontramos chullpas incaicas en número

\footnotetext{
1 El presente trabajo ha sido posible gracias a las entrevistas realizadas a los qasirinos, residentes en Lima, el domingo 21 de agosto en la fiesta patronal —en Villa María del Triunfo- en honor a la Virgen de las Nieves, patrona de Qasiri.

2 El Dr. Alberto Bueno es profesor principal de la Escuela de Arqueología de facultad de Ciencias Sociales, UNMSM.
} 
crecido, algunas de las cuales fueron observadas por los excursionistas escolares y encontraron momias las que estaban con sus indumentarias domésticos (mates, tinajas, puyños, ollas, etc.) cuyos fragmentos fueron recogidos para el museo escolar".

De igual forma, en otras zonas del distrito de Pausa se han encontrado construcciones viales incas, del cual podemos afirmar la ocupación de los Tahuantinsuyo en esta zona. Este camino inca que pasa por Qasiri tendría una llegada a Inca-Wasi, construcción inca que se ubica en Pausa, el cual habría sido utilizado como depósito de armamentos y de centro de acopio de la producción.

La sociedad andina, como indica el Dr. Lumbreras, se desarrolló con una lógica vinculada más a la idea de construcción que a la de destrucción. En un diálogo con él señala: "nosotros solo peleamos cuando nos defendemos". Y Qasiri no es una excepción. Los qasirinos desarrollaron, desde sus inicios, la lógica de intercambio y de reciprocidad, manteniendo de esta manera vínculo con otros pueblos.

Con la llegada de los españoles, Qasiri fue parte de muchos cambios políticos y sociales. Entre los más resaltantes se encuentran los efectos de la política de las reducciones y la formación de los corregimientos, emprendidas por el virrey Toledo. Parinacochas desde entonces pasó a ser uno de los corregimientos, dividido en cuatro repartimientos: repartimiento de Parinacochas, Collanas, Pomatambos y el de Guaynacotas. El repartimiento de Parinacochas tuvo como centro de administración a Pausa, siendo Casiri uno de los principales ayllus de este repartimiento (García Cuellar: 1950, 83-84).

En el trabajo de este mismo autor, Filiberto García Cuellar, existe una relación de indios tributarios del pueblo de Pausa en 1744, precisamente en el gobierno del virrey José Antonio de Mendoza (1736-1745)³.

En la República, Qasiri o Casire se convierte en anexo del distrito de Pausa, provincia de Parinacochas; y en 1985, se crea la provincia del Paucar del Sara Sara con la capital de Pausa.

A pesar de la ocupación colonial, Qasiri mantuvo muchas características de una sociedad andina, siendo el trueque un ejemplo claro; pero es necesario indicar que muchas de estas costumbres y tradiciones, con la ocupación colonial, han pasado por un proceso de préstamos e imposiciones culturales. Su economía principal fue siempre la agricultura, teniendo como actividad complementaria la crianza de cerdos, carneros y vacas. Y en las últimas décadas, según los entrevistados, el intercambio recíproco viene disminuyendo, mientras el comercio es creciente.

En la década del 90, durante el gobierno de Alberto Fujimori, la carretera llegó a Qasiri, lo que facilitó la comunicación y conexión con otros pueblos. Para los qasirinos la carretera el inicio del progreso: "las casas empezaron a techarse con tejas y calaminas". Además, recuerdan de este gobierno el regalo de un vehículo que hizo a la comunidad.

En el año 2001 Qasiri fue afectado por un terremoto que produjo daños materiales, generando la mudanza masiva a la parte alta. Don Eulogio Quispe, uno de nuestros entrevistados en la fiesta de la Virgen de las Nieves en Lima, expresa que

\footnotetext{
3 Véase Filiberto García Cuellar (1950: 175).
} 
después del terremoto, el pueblo fue reconstruido, con adobes y material noble, con ayuda de las autoridades: "El pueblo antiguo quedó en ruinas", construcción hecha de piedra y barro.

\section{Evolución demográfica}

Qasiri, desde tiempos antiguos siempre tuvo una población reducida, teniendo una tasa de natalidad muy baja, debido a que los niños morían en su mayoría a los 3 ó 4 años de edad, a efectos de viruela y el paludismo. Los hombres siempre salieron en busca del trabajo a otros pueblos: ya sea como arrieros o mineros, por lo que las mujeres casi siempre quedaban solas en el pueblo, teniendo en sus manos la mayoría de las responsabilidades. La reducida cantidad de hombres, según las creencias religiosas, se debería en que la virgen no permitía vivir a los hombres en Qasiri.

Por su parte María Rostworowski ${ }^{4}$ en su libro Ensayos de historia andina II, pampas de Nasca, género, hechicería (2005), entrevista la película realizada por Marianne Eyde en el año 1980, cuando aún Qasiri pertenecía al distrito de Pausa, provincia de Parinacochas: "Casire está situado en las faldas del volcán Sara-Sara. Se trataría de un pueblo de mujeres y, según la tradición, los hombres no podrían permanecer en él más de tres meses, pues corrían el riesgo de morir. Cuenta la historia, que el Sara Sara asestó un golpe con una barreta a la cabeza del Coropuna, cerro vecino, y lo partió en cuatro partes. En represalia Coropuna golpeó al Sara-Sara y lo dividió en dos; surgiendo del lado negro el volcán Sulcaymarca que era macho. Después de la pelea Sara Sara se convirtió en hembra y macho y ya no necesitó del Coropuna. El Sara Sara Mujer ganó la partida al Coropuna varón.

Es interesante constatar que en este pueblo de mujeres los cargos públicos estuvieron en manos femeninas. Así tenemos que la mayordoma es una viuda y lo mismo la alcaldesa repartidora del agua. Al terminar su mandato y luego de haber cumplido cabalmente su gestión ellas eran despedidas con música y baile. En la región el riego también estaba a cargo de las mujeres solteras y viudas" Eyde (2005: 41).

Por los años 40 del siglo pasado la población inicia a decaer debido a la migración de los qasirinos hacia las ciudades como Pausa, Chala, Ica, Lima, etc. en búsqueda de mejores oportunidades. Cuatro décadas más adelante la migración aceleró, por lo que lo el pueblo fue despoblándose y paralelamente las casas fue deshabitándose. Por estos años, no solo los hombres migran de Qasiri, sino, también las mujeres en búsqueda de nuevas oportunidades: educación para sus hijos o un puesto trabajo.

Según don Eulogio, en la actualidad Qasiri cuenta con no más de diez familias. Entre ellos, los apellidos más reconocidos y comunes son: Taipe, Escobar, De la Cruz, Teves, Huamani, Rodríguez, entre otros. La educación en este pueblo continúa con dificultades, solo cuenta con inicial y primaria, por lo que se ven obligados a salir para estudiar secundaria en Pausa o a otras ciudades.

$4 \quad$ Disponible en http://books.google.com.pe (revisado el 29 de junio del 2012). 


\section{Fiesta de la Virgen de las Nieves en la Asociación Progresista Hi- jos de Qasiri en Lima}

Según cuenta la leyenda, cuatro vírgenes aparecieron en Qasiri, de las cuatro hermanas: virgen de las nieves, la de Cora-Cora, la de Chumpi y la de Copacabana. La Virgen de las Nieves quiso quedarse, diciendo: "yo me quedo en Casire y aquí me hacen mi iglesia" y se quedó sentada sobre una piedra. A partir de esto los pobladores la nombraron su patrona.

Esta festividad religiosa se realiza en el pueblo de Qasiri (departamento de Ayacucho) y está dividida en dos partes: fiesta principal de la virgen que se realiza el 5 de agosto y fiesta del niño que se realiza el 6 de agosto.

"La Asociación Progresista Hijos de Casire" está ubicada en el distrito de Villa María del triunfo y fue fundada en 1976, teniendo por objetivo la reagrupación de los qasirinos residentes en la capital de Lima y la fiesta de la Virgen de las Nieves forma parte de su identidad oficial en la urbe de tradición occidental desde el mundo colonial, razón por la cual reproducen cada año.

Por tal motivo el domingo 21 de agosto del 2011 nos dirigimos hacia la institución hijos de Qasiri para presenciar el desarrollo de esta festividad religiosa. Y llegamos al lugar en momentos de la salida de la Virgen de las Nieves, en procesión de la casa del mayordomo, acompañados por la banda musical y un grupo de huaylías conformada por hombres y mujeres. En este caso, las huaylías encargadas de recibir a la virgen provenían del distrito de Quilcata de Pausa.

En el trayecto la procesión se detuvo en la ermita de San Roque, para un aludo recíproco y realizarlo un pequeño convite, como símbolo de recepción en el barrio y de honrar su fiesta anual. La virgen al llegar al local de la asociación se ubicó en su altar central decorado estupendamente de flores, luces y brillos; y la población que los aguardaban y los invitados salen al encuentro y terminan en abrazos y bromas de camaradería por el gran reencuentro. Mientras tanto, los encargados preparaban la realización de la misa entre la música de las huaylías de Qasiri y de Quilcata; y la recepción concluye con el saludo oficial de la "sargentana", a cargo de una niña, como fija la tradición. Los qasirinos precisan que solo las solteras y niñas puede ocupar este cargo, pues se entregan puras a la virgen: La sargentana llevaba una franja de tela encima, al cual cuelgan billetes como donación de sus familiares y paisanos devotos.

Los Alférez de esta festividad son: John Orellano Molina, Peregrina Molina (mamá), Marlín Mitma (esposa), Mayordomo: Teodoro Castillo y su esposa Edilmira Cruzate.

Alférez de la Virgen: Felipe Cruzate y su esposa María Quispe.

Alférez del niño: Emidia Escobar Pebe y su hija Noemí Becerra.

Primera Sargentana: Liz Taipe de la Cruz y padre.

Segunda Sargentana: Milagros Taquire de la Cruz.

Los organizadores de esta gran festividad, son generalmente aquellos descendientes de los pobladores de Qasiri, que desean seguir el legado de sus padres. 
Asimismo, a esta festividad no solo acuden los pobladores de la misma comunidad, sino, también participan las personas de otras comunidades a modo de reciprocidad, pues esperan que también asistan a sus festividades.

\section{Inmigración a Lima}

a) Primeros migrantes: Ubicación, trabajo y educación.

Las migraciones realizadas por los pobladores de Qasiri iniciaron alrededor de los años 40 del siglo pasado, principalmente hacia la costa peruana, siendo la capital nacional uno de los destinos. En Lima los qasirinos se ubicaron en los distritos de San Martin de Porres, Barranco, San Juan de Miraflores y principalmente en los distritos de Villa María del Triunfo, Callao y Chosica. Estos primeros inmigrantes realizaron, muchas veces, trabajos de subsistencia y se dedicaron también al comercio de algunos productos agrícolas producidos por ellos mismos. A pesar de la difícil situación urbana, los qasirinos alcanzaron estudiar la primaria como la secundaria y algunos, las carreras técnicas. Mientras las generaciones siguientes lograron conseguir un nivel de vida más cómodo que el de sus antecesores, sobre todo con el acceso a la educación superior se profesionalizaron ya sea de abogados, ingenieros, enfermeros, secretarias, mecánicos, etc.; quienes propician superación a sus hijos y a las nuevas generaciones.

\section{ENTREVISTAS}

Don Eulogio

Marcela Neira: Ella no es propiamente de Qasiri sino de Cahuachi (Arequipa), pueblo vecino y conocedora de las tradiciones.

Don José Hipólito Escobar Taype: qasirino migrante que reside en Villa María del Triunfo.

María Taype: Qasirina desde hace muchos años y reside en Lima.

Isabel Tevez: Qasirina que reside en Villa María del Triunfo.

Juan de la Cruz: Reside en Villa María del Triunfo.

\section{BIBLIBOGRAFÍA}

\section{FILIBERTO CUELLAR}

1950 Monografía sobre la provincia de Parinacochas.

LIBRO VIRTUAL: ROSTWOROWSKI DE DIEZ CANSECO, María

2005 Ensayos de historia andina II, pampas de Nasca, género,Hechicería. Lima: Instituto de Estudios Peruanos. P.41. 225 pp. 